\title{
Predictors of Functional Impairment in Children and Adolescents
}

\author{
Lourdes Ezpeleta, Roser Granero, Nuria de la Osa, and Noemí Guillamón \\ Universitat Autònoma de Barcelona, Spain
}

\begin{abstract}
The goal of this study was to investigate the variables that best predict functional impairment in children and adolescents. Two hundred and eight psychiatric and 129 pediatric children aged 7 to 17 years were assessed with measures of psychopathology, functional impairment, temperament, marital discord, educational style, coping, developmental milestones, stressful life events, medical history, school information, and family history of psychopathology. Multiple regression models adjusted by psychopathology were estimated. The global model, which included all the significant variables in partial models, revealed the following predictors of impairment: receiving review lessons, chronic disease or handicap, the presence of problems the child interpreted as stressful, late onset and long duration of psychopathological problems. These indicators could be useful for the proper identification of children with severe difficulties, in order to provide them with adequate psychological services.
\end{abstract}

Keywords: Functional impairment, predictors, child and adolescent psychopathology, CGAS.

Abbreviations: A-COPE: Adolescent-Coping; CGAS: Children's Global Assessment Scale; CPQ: Children's Perceptions Questionnaire; DICA-R: Diagnostic Interview for Children and Adolescents-Revised; EMBU: Early Memories of Parental Rearing; R-DOTS: Revised Dimensions of Temperament Survey.

In the last few years a vivid debate has taken place about the definition of mental disorder. The discussion was originated by a lack of agreement about what psychopathology is and Wakefield's (1992) proposal of defining mental disorder as a harmful dysfunction. Clark (1999) and Nathan and Langenbucher (1999) have synthesized the many different positive and negative criticisms written so far. Although it is not the point of this paper to discuss the proper definition of mental disorder, the context of this debate highlights the importance of knowing the variables most related to functional impairment.

The terms impairment, disability, and handicap refer to the different consequences that a disorder could cause at the level of the function, the person, or the life roles respectively (WHO, 1999). To know the degree to which a person is incapacitated is important for the identification of "normal" and "abnormal" behaviors (noncases and cases). This is especially true in epidemiological more than in clinical samples (Bird et al., 1990; Weissman, Warner, \& Fendrich, 1990) because of the less marked symptomatology in the former. Different authors have shown the importance of including impairment indicators in the diagnostic definitions in order to reduce the prevalence rates of the disorders (Bird et al., 1988; Roberts, Roberts, \& Chen, 1997; Shaffer, Fisher, Dulcan, \& Davies, 1996; Simonoff et al., 1997). The knowledge of the degree of impairment is also necessary for the proper

Requests for reprints to: Lourdes Ezpeleta, Universitat Autònoma de Barcelona, Departament de Psicologia de la Salut i Psicologia Social, Edifici B, 08193 Bellaterra (Barcelona), Spain (E-mail: lourdes.ezpeleta@uab.es). identification of those persons affected by a psychological disorder or in need of psychological help. Once the affected persons and the level of impairment are identified, a specific treatment or service can be recommended. In this sense, Hodges and Wong (1997) reported that the total score of impairment was the best predictor of service utilization when compared with other measures of psychopathology. McArdle and Gillett (1997), in a sample of inpatients and outpatient children, found that the principal determinant of admission was the degree of clinical impairment. Similar results were found by Lyons et al. (1997) with respect to readmission. In preschool children attending pediatric primary care, Lavigne et al. (1998) found that greater functional impairment was associated with more visits to the emergency department and fewer visits to primary care, and that health care use was significantly related to child psychopathology. Finally, Settertobulte and Kolip (1997) studied the determinants of consultation in a sample of adolescents of the general population. One of the most significant predictors of consultation was the degree of subjective impairment. So, information about impairment is also useful for assigning treatments or services. Finally, impairment indicators can also be used as outcome indices. Green, Shirk, Hanze, and Wanstrath (1994) consider that, in those cases where the highest and the lowest level of impairment are identified, the first could be used as an outcome measure and the second as a measure of severity. Hodges, Wong, and Latessa (1998) also found that impairment was among the significant predictors of change over time in two clinical samples. In a 6-year longitudinal study Verhulst, Eussen, Berden, Sanders-Woudstra, and Van der Ende (1993) revealed that "persisters", that is, those children still deviant at follow-up, had the higher impairment when compared with "increasers" and 
"decreasers". Recently, Costello, Angold, and Keeler (1999) indicate that the level of functional impairment in childhood was predictive of the effects of childhood psychiatric disorders in adolescence.

At the level of relationships, we know that impairment measures have been associated with comorbidity: the most impaired cases present more comorbidity (Bird et al., 1993; Newman et al., 1996). Also impairment measures have been significantly correlated with diagnosis, number of diagnoses, social, adaptive and instrumental competence, average grades, suspensions, expulsions or poor attendance at school, and difficulties with laws (Bird, Canino, Rubio-Stipec, \& Ribera, 1987; Bird et al., 1993; Hodges, Doucette-Gates, \& Liao, 1999). However, few studies have approached the topic of predictors of impairment. Manassis and Hood (1998) determined the correlates of anxiety disorders that were predictive of impairment. They concluded that predictors were different depending on disorder. Thus, the impairment for generalized anxiety disorder was mainly determined by psychosocial adversity, but in the case of phobia, it was determined by mothers' ratings of conduct problems of the child, the depressive symptoms reported by the child, the maternal phobic anxiety, and the development difficulties suffered by the child. In another study in an older community sample (15-54 years), Curtis, Magee, Eaton, Wittchen, and Kessler (1998) found that the number of fears strongly predicted impairment.

Recently, the topic of impairment has gained interest, as the Diagnostic and statistical manual of mental disorders (APA, 1994) has included in the definition of many disorders the existence of significant impairment in important areas of the individual's activities. Consequently, the assessment of psychopathology must include not just an evaluation of the symptoms, but also an assessment of the level of impairment they cause.

The goal of the study was to investigate the variables that best predict impairment. The knowledge of these variables could permit evaluators: (1) to detect those situations that could be prognostic in psychological disorders; (2) to detect risk situations of great impairment and intervene in time in order to reduce the effects of the situation; and (3) to extend the knowledge about the developmental pathways that antecede impairment.

\section{Method}

\section{Subjects}

The sample included 337 children and adolescents from 7 to 17 years of age. In the psychiatric group there were $208(62 \%)$ outpatient children with a mean age of 12.8 years $(S D 3.1)$ recruited from 3 primary mental health services for children and adolescents. Forty-four per cent $(N=91)$ were boys and $56 \%$ $(N=117)$ girls. Following the Hollingshead Socioeconomic Index (1975), 91\% were associated with low and mean low levels and $9 \%$ to high-mean high. Ninety-one per cent of the children in this group had some psychopathological syndrome.

The pediatric group was comprised of $129(38 \%)$ outpatient children with a mean age of 11.6 years $(S D 3.1)$. They attended consultation due to minor physical problems and were included in the study because they agreed to participate in it. Thirty-eight per cent $(N=49)$ were boys and $62 \%(N=80)$ were girls. Eighty-seven per cent were associated with low-mean low levels and $13 \%$ to high-mean high on the Hollingshead Index. Fiftyseven per cent of the children in this group had some psychological disorder.

\section{Measures}

Diagnostic status was established with the Diagnostic Interview for Children and Adolescents-Revised (DICA-R; Reich, Shayka, \& Taibleson, 1991) in three versions: for children, adolescents, and parents. The DICA-R is a semistructured diagnostic interview that covers the most frequent diagnostic categories in children and adolescents following DSM-III-R definitions (APA, 1987). It includes a section pertaining to psychosocial stresses and developmental milestones (Reich, 1992). The DICA-R has been adapted and validated for the Spanish population with satisfactory psychometric properties (Ezpeleta, de la Osa, Doménech, Navarro, \& Losilla, 1995, 1997; Ezpeleta, de la Osa, Júdez, Doménech, Navarro, \& Losilla, 1997; Granero, Ezpeleta, Doménech, \& de la Osa, 1998; de la Osa, Ezpeleta, Doménech, Navarro, \& Losilla, 1996, 1997).

For the assessment of impairment, the Children's Global Assessment Scale (CGAS; Shaffer et al., 1983) was used. It was created as a unidimensional scale that synthesizes the level of functioning of the child with only one score. The scale ranges from 1 (maximum impairment) to 100 (normal functioning). The authors note that the scale could be appropriate for children aged 4 to 16 years old. Scores higher than 70 indicate normal adaptation. Results about the psychometric properties of CGAS have been presented with part of the sample of this study. Reliability (test-retest, inter-interviewer, and parentchild agreement) and validity (discriminant) were good (Ezpeleta, Granero, \& de la Osa, 1999).

The Revised Dimensions of Temperament Survey (R-DOTS; Windle \& Lerner, 1986) assesses the nine temperamental dimensions described by Thomas and Chess, through the information of parent or children, depending on age.

Family conflict was assessed with the Children's Perceptions Questionnaire (CPQ; Emery \& O'Leary, 1982), which is composed of two scales: marital discord and acceptance.

Educational style was evaluated with the EMBU (Early Memories of Parental Rearing; Perris, Jacobson, Lindström, Knorring, \& Perris, 1980, adapted by Castro, Toro, Van der Ende, \& Arrindell, 1993). Children and parents answered questions on the four scales: rejection, overprotection, emotional warmth, and favoring subject.

Adolescent-Coping (A-COPE; Patterson \& McCubbin, 1987) was used to assess the style the child reports for coping with the problems. The 12 scales that form the A-COPE are displayed in Table 1.

A demographic questionnaire, answered by parents, collected information about their education, profession, and family history of psychopathology.

\section{Procedure}

After obtaining informed written consent from parents and oral assent to participate in the study from children, different interviewers previously trained in the use of the DICA-R interviewed the children and the parents. After the interview, they assigned the lowest CGAS score of the present time (the previous month) based on the information obtained in the interview. Interviewers did not have previous information of the child besides the answers to DICA-R. Later, parents and children answered the questionnaires.

Through multiple regression models, adjusted by psychopathology (presence/absence of any disorder in the DICA-R), variables that predict the degree of impairment were examined. The dependent variable was the lowest CGAS score obtained after the parent or the child interview. Different partial models were built clustering independent variables by similarity of content (Table 1). The categorical independent variables were introduced in the model and coded using the reference cell method. Finally, we built a global model including the significant variables resulting in the individual models, with the 
Table 1

Independent Variables Included in Multiple Regression Models

Demographic variables and other mixed variables: Sex, age, order in the siblings, number of persons living in the house, socioeconomic status, family history of psychopathology, school variables (need of review lessons, repeating courses, number of suspensions and expelling), medical problems (chronic diseases or handicaps, hospitalization, allergies, diet, medication, recent disease).

Temperament: General activity level, activity level during sleep, approach/withdrawal, flexibility-rigidity, mood, rhythmicity-sleep, rhythmicity-eating, rhythmicity in daily habits, task orientation, distractibility, persistence (R-DOTS).

Developmental problems: Pregnancy problems (bleeding, vomiting, lost of weight, infections, hypertension, convulsions, emotional problems, medication, smoking, alcohol, drugs), delivery problems, postnatal problems (incubator, birthweight, hospitalization, surgery, breast-feed, excessive crying, hypertonia, hypotonia), early development (sit up, crawl, walk, use of words, sentences, sphincter control), nursery school, problems in preschool years (ran off, hyperactivity, impulsive behavior, excitability, temper tantrums, destructive, very demanding, aggressive behavior, clumsiness).

Stressful life events: Worries about the family, fights at the house, separation/divorce, economical problems, deaths, alcohol problems in the family, legal problems in the family, fear of being battered, physical maltreatment in the child or other member of the family, other problems.

Total number of problems in the studied categories: Total number of stressful life-events, total number of problems during pregnancy, delivery, infancy years, or in the development, and total number of hospitalizations.

Age of onset and duration of psychopathology

Age of onset and duration of the child school and medical problems: Age and duration of review lessons, repeating courses, suspensions, and medical problems.

Educational style (separate for parents and children): Favouring subject, overprotection, rejection and emotional warmth (EMBU).

Coping: Ventilating feelings, seeking diversions, developing self-reliance, developing social support, solving family problems, avoiding problems, seeking spiritual support, investing in close friends, seeking professional support, engaging in demanding activity, being humorous, relaxing (A-COPE).

Marital discord: Marital discord and acceptance of the child (CPQ).

exception of coping style because the age of application excluded a lot of children.

The sample size changes within the different models because of the ages for which the questionnaire were appropriate, the informant for whom the questionnaire was designed, and missing data (informants who did not want to answer the questionnaires). Therefore, we checked that in every model the distribution of sex, age, and psychopathology was not statistically different from that of the original sample.

\section{Results}

Almost all the partial models, with the exception of the models of age of onset and duration of school and medical problems, resulted in predicting variables of CGAS ( Table 2).

Starting with the partial models, age was the only demographic variable important in determining the level of impairment: older children had more deterioration in their daily occupation. Among the mixed variables, to have received review lessons, to have been suspended from school more than twice, and to suffer a chronic disease or handicap were predictive of a significant degree of impairment. Children who suffered these situations had lower impairment scores, meaning they had a higher functional impairment. This model explained the highest variability of the CGAS score ( $49 \%$ total, and $20 \%$ excluding psychopathology).

The temperamental dimension predictive of impairment was a high level of general activity. High flexibility, high positive mood, and low distractibility improved the quality of functioning. The whole model explained $33 \%$ of CGAS variability, and the dimensions alone explained $14 \%$.

Pregnancy and delivery hazards were not influential for determining the level of current impairment and, among postnatal and developmental variables, only surgical interventions during the first month of life seemed very predictive of the level of impairment later in life. Children who had such interventions scored 31 points lower $(95 \%$ CI: 12 to 50) on impairment (were more impaired) than those who did not. The variability of CGAS explained for this model was the lowest $(23 \%)$. The contribution of surgical intervention for explaining functioning was just $3 \%$.

Among the stressful life events, to have been physically maltreated or the presence of problems other than fights, separations or divorce, economical difficulties, deaths, alcohol, or police problems caused a decrease in CGAS scores of 9 points ( $95 \% \mathrm{CI}: 2$ to 16 in both cases). Considering the total number of problems, only the total number of stressful events predicted deterioration. The presence of each event was related to a CGAS score declining 2 points ( $95 \% \mathrm{CI}: 1$ to 3$)$, indicating that the more stressful events resulted in the most impairment. A child with four stressful events could score up to 12 points lower.

The model including age of onset and duration of the problem indicates that, when the problem starts at a greater age and has a long duration, the impairment is higher. For each month that the problem exists, the CGAS score diminishes 0.13 points; that is, for every 8 months of problem duration, the CGAS is reduced by 1 point. Results of age of onset indicate that for every year by which the age of onset of the problem is increased, the CGAS score diminishes by almost 1 point.

With regard to the contribution of educational style in the prediction of impairment, based on information from the parents, maternal emotional warmth predicted less impairment, but maternal overprotection predicted more. According to the information obtained from the child, rejection by the mother and overprotection by the father were the most predictive of dysfunction. The children's model explained more variability of CGAS (35\% global; $17 \%$ adjusted) than did the parent model $(24 \%$ and $5 \%$ adjusted).

The coping strategies of developing self-reliance and 
Table 2

Models Predictive of Impairment (CGAS Score)

\begin{tabular}{|c|c|c|c|c|c|}
\hline \multirow[b]{2}{*}{ Model } & \multicolumn{2}{|c|}{ Nonstandardized coefficients } & \multirow{2}{*}{$\frac{\text { Standardized coefficients }}{\beta}$} & \multirow{2}{*}{ Significance } & \multirow{2}{*}{$\begin{array}{l}95 \% \text { confidence } \\
\text { interval of B }\end{array}$} \\
\hline & B & SE & & & \\
\hline \multicolumn{6}{|l|}{ Demographic \& mixed $(N=172)$} \\
\hline Constant & 96.408 & 4.143 & & & \\
\hline Psychopathology & -14.730 & 2.388 & & & \\
\hline Age & -1.604 & 0.364 & -0.297 & .000 & -2.324 to -0.885 \\
\hline Review lessons & -5.440 & 2.225 & -0.165 & .016 & -9.833 to -1.047 \\
\hline Suspensions (1-2) & 3.848 & 3.054 & 0.074 & .209 & -2.182 to 9.878 \\
\hline Suspensions $(\geqslant 3)$ & -4.913 & 2.144 & -0.138 & .023 & -9.146 to -0.680 \\
\hline Chronic diseases or handicaps & -8.965 & 4.372 & -0.115 & .042 & -17.598 to -0.332 \\
\hline \multicolumn{6}{|l|}{${ }^{\mathrm{a}} \mathrm{R}^{2}=.20 ;{ }^{b} \mathrm{R}^{2}=.49$} \\
\hline \multicolumn{6}{|l|}{ Temperament $(N=240)$} \\
\hline Constant & 42.674 & 7.996 & & & \\
\hline Psychopathology & -13.636 & 2.150 & & & \\
\hline General activity level & -0.360 & 0.178 & -0.119 & .044 & -0.710 to -0.010 \\
\hline Flexibility & 0.742 & 0.271 & 0.155 & .007 & 0.208 to 1.276 \\
\hline Mood & 0.744 & 0.176 & 0.235 & .000 & 0.397 to 1.092 \\
\hline Distractibility & 0.387 & 0.190 & 0.117 & .043 & 0.012 to 0.761 \\
\hline \multicolumn{6}{|l|}{${ }^{\mathrm{a}} \mathrm{R}^{2}=.14 ;{ }^{b} \mathrm{R}^{2}=.33$} \\
\hline \multicolumn{6}{|l|}{ Development $(N=246)$} \\
\hline Constant & 75.129 & 1.923 & & & \\
\hline Psychopathology & -17.377 & 2.148 & & & \\
\hline Surgery at 1 month & -31.441 & 9.628 & -0.184 & .001 & -50.405 to -12.476 \\
\hline \multicolumn{6}{|l|}{${ }^{\mathrm{a}} \mathrm{R}^{2}=.03 ;{ }^{\mathrm{b}} \mathrm{R}^{2}=.23$} \\
\hline \multicolumn{6}{|l|}{ Stressful life events $(N=215)$} \\
\hline Constant & 74.452 & 1.980 & & & \\
\hline Psychopathology & -15.043 & 2.247 & & & \\
\hline Physical abuse to the child & -9.181 & 3.325 & -0.171 & .006 & -15.735 to -2.627 \\
\hline Other problems & -9.404 & 3.623 & -0.162 & .010 & -16.546 to -2.262 \\
\hline \multicolumn{6}{|l|}{${ }^{\mathrm{a}} \mathrm{R}^{2}=.07 ;{ }^{\mathrm{b}} \mathrm{R}^{2}=.26$} \\
\hline \multicolumn{6}{|l|}{ Total no. of problems $(N=304)$} \\
\hline Constant & 79.067 & 1.720 & & & \\
\hline Psychopathology & -17.873 & 1.925 & & & \\
\hline Total number of stressful events & -1.876 & 0.445 & -0.209 & .000 & -2.753 to -1.000 \\
\hline \multicolumn{6}{|l|}{${ }^{\mathrm{a}} \mathrm{R}^{2}=.04 ;{ }^{\mathrm{b}} \mathrm{R}^{2}=.30$} \\
\hline \multicolumn{6}{|l|}{ Age and duration $(N=310)$} \\
\hline Constant & 91.206 & 3.320 & & & \\
\hline Pyschopathology & -16.421 & 1.815 & & & \\
\hline Age of onset of psychopathology & -0.944 & 0.282 & -0.256 & .001 & -1.500 to -0.388 \\
\hline Duration of the problem (month) & -0.126 & 0.020 & -0.494 & .000 & -0.165 to -0.088 \\
\hline \multicolumn{6}{|l|}{${ }^{\mathrm{a}} \mathrm{R}^{2}=.11 ;{ }^{\mathrm{b}} \mathrm{R}^{2}=33$} \\
\hline \multicolumn{6}{|l|}{ Educational style parents $(N=224)$} \\
\hline Constant & 65.478 & 9.875 & & & \\
\hline Psychopathology & -14.134 & 2.437 & & & \\
\hline Warmth mother & 0.351 & 0.130 & 0.163 & .007 & 0.096 to 0.607 \\
\hline Overprotection mother & -0.322 & 0.141 & -0.142 & .024 & -0.601 to -0.044 \\
\hline \multicolumn{6}{|l|}{${ }^{\mathrm{a}} \mathrm{R}^{2}=.05 ;{ }^{\mathrm{b}} \mathrm{R}^{2}=.24$} \\
\hline \multicolumn{6}{|l|}{ Educational style children $(N=216)$} \\
\hline Constant & 86.599 & 2.892 & & & \\
\hline Psychopathology & -12.698 & 2.237 & & & \\
\hline Rejection mother & -0.269 & 0.093 & -0.259 & .004 & -0.452 to -0.086 \\
\hline Overprotection father & -0.309 & 0.143 & -0.190 & .032 & -0.592 to -0.027 \\
\hline
\end{tabular}




\begin{tabular}{|c|c|c|c|c|c|}
\hline \multirow[b]{2}{*}{ Model } & \multicolumn{2}{|c|}{ Nonstandardized coefficients } & \multirow{2}{*}{$\frac{\text { Standardized coefficients }}{\beta}$} & \multirow[b]{2}{*}{ Significance } & \multirow{2}{*}{$\begin{array}{l}95 \% \text { confidence } \\
\text { interval of } B\end{array}$} \\
\hline & $\mathrm{B}$ & SE & & & \\
\hline \multicolumn{6}{|l|}{ Coping style $(N=115)$} \\
\hline Constant & 82.025 & 6.622 & & & \\
\hline Psychopathology & -13.242 & 3.914 & & & \\
\hline Developing self-reliance & -1.024 & 0.373 & -0.240 & .007 & -1.762 to -0.286 \\
\hline Seeking professional support & 1.436 & 0.705 & 0.166 & .044 & 0.038 to 2.834 \\
\hline Investing in close friends & -2.187 & 0.712 & -0.277 & .003 & -3.599 to -0.775 \\
\hline \multicolumn{6}{|l|}{${ }^{\mathrm{a}} \mathrm{R}^{2}=.18 ;{ }^{\mathrm{b}} \mathrm{R}^{2}=.30$} \\
\hline \multicolumn{6}{|l|}{ Marital discord $(N=215)$} \\
\hline Constant & 53.361 & 5.675 & & & \\
\hline Psychopathology & -15.993 & 2.423 & & & \\
\hline Marital harmony & 0.817 & 0.199 & 0.247 & .000 & 0.424 to 1.210 \\
\hline \multicolumn{6}{|l|}{${ }^{\mathrm{a}} \mathrm{R}^{2}=.06 ;{ }^{\mathrm{b}} \mathrm{R}^{2}=.24$} \\
\hline \multicolumn{6}{|l|}{ Global model $(N=138)$} \\
\hline Constant & 96.153 & 4.387 & & & \\
\hline Psychopathology & -11.586 & 2.543 & & & \\
\hline Review lessons & -6.651 & 2.323 & -0.211 & .005 & -11.247 to -2.055 \\
\hline Chronic diseases or handicaps & -12.764 & 4.736 & -0.166 & .008 & -22.133 to -3.396 \\
\hline Other stressful events & -11.932 & 3.980 & -0.188 & .003 & -19.804 to -4.059 \\
\hline Age of onset psychopathology & -1.660 & 0.434 & -0.410 & .000 & -2.519 to -0.802 \\
\hline Duration of the problem (month) & -0.136 & 0.031 & -0.519 & .000 & -0.198 to -0.074 \\
\hline${ }^{\mathrm{a}} \mathrm{R}^{2}=.27 ;{ }^{\mathrm{b}} \mathrm{R}^{2}=.50$ & & & & & \\
\hline
\end{tabular}

\footnotetext{
${ }^{a}$ Contribution of the predictors (excluding the psychopathology effect).
}

${ }^{\mathrm{b}}$ Final fitted model.

confiding in close friends were indicative of more impairment. Those who sought professional support for problems functioned better. This model explained 30\% of CGAS variability ( $18 \%$ adjusted).

Finally, marital discord scores were also predictive of dysfunction, and for each point that marital harmony increases, the CGAS increases 0.82 points, indicating good functioning.

The results concerning the global model suggest that the most relevant predictive variables of a low CGAS score were: to receive review lessons, chronic diseases or handicaps, other problems the child interpreted as stressful, older age of onset, and long duration of psychological problems. None of variables of temperament, development, the total number of problems, coping style, educational style, nor marital discord supplied relevant information for explaining child dysfunction. In the global model, the effects of the variables were higher than in the partial models. The final model explained $50 \%$ of variability of CGAS and, excluding psychopathology, the contribution of the predictive variables was $27 \%$.

\section{Discussion}

Our results indicate that there are several situations that can lead to an alteration of the functioning of the normal life of children and adolescents, severe enough to cause them problems.

The variability explained by the models was, in general, moderate (ranging from $23 \%$ to $49 \%$ ). However, when the psychopathology was controlled it oscillated in the low range (from $3 \%$ to $20 \%$ ). Although, by definition, psychopathology is the most important variable predicting impairment and different studies have demonstrated the relationship between psychopathology and measures of impairment (Bird et al., 1987, 1990, 1993;
Gureje \& Omigbodun, 1995; Verhulst et al., 1993), this topic is controversial. Green et al. (1994) have pointed out that the severity of the symptoms and the functioning of the child do not necessarily correspond. In clinical samples, these authors indicate that impairment measures are related to competence more so than to symptomatology, suggesting that clinical raters are more likely to consider competence than symptomatology when they evaluate impairment. Further, Angold, Costello, Farmer, Burns, and Erkanli (1999) noticed that children with functional impairment but without a diagnosis were as disturbed as children with a well-defined diagnosis. Contrary to that finding, Apter, Orvaschel, Laseg, Moses, and Tyano (1989) showed that the CGAS assesses different aspects to those evaluated by the social competence scales of the CBCL (Achenbach, 1991). And further, Shaffer et al. (1983) indicate that the CGAS taps different domains to those evaluated by the Conners checklist (Conners, 1969). Our goal was not to assess the contribution of psychopathology as a predictor of impairment, but rather the contribution of other factors related to the environment or the life of the subjects. Moreover, the procedure followed for assigning CGAS scores in this study was based mainly in the information obtained in the diagnostic interview, ignoring the other events in the life of the child. For this reason we adjusted the models by psychopathology.

Supensions from school seem to be a good indicator of the existence of severe alterations in functioning. In general, this behavior is common in children with externalizing problems. In Verhulst's study, children with externalizing problems were suffering chronic difficulties ("persisters") and they were the group with higher impairment. Similarly, children who need review lessons are those whose school functioning is altered because of school failure. Other studies have documented the predictive power of school failure for disruptive disorders 
(Grizenko \& Pawliuk, 1994) or their associations with other negative behaviors (Brier, 1995). For the purpose of detecting risk situations that mark the severity of disturbed psychosocial functioning, suspensions or school failure could be objective signs of alarm.

Different studies have showed the risk for maladjustment is increased in children with chronic illness (Lewis, 1994). As Padur et al. (1995) indicate, the degree of alteration depends on the condition suffered. In their study, asthmatic children had a greater functional impairment when compared with children with cancer, diabetes, or without health problems. But, most important, these authors suggest that functional status could be a mediational variable between asthma and affective disorders. Follow-up medical consultations in children with chronic medical conditions or handicaps should consider how the child functions in the different behavioral domains and even include impairment measures in the assessment schedules of these children, as Harris, Canning, and Kelleher (1996) recommend.

The temperamental dimensions have been demonstrated to have predictive specificity for later psychopathology (Caspi, Henry, McGee, Moffitt, \& Silva, 1995). The interaction between temperamental dimensions and other biological, relational, or environmental variables have a predictive impact on the way the child adapts or reacts to situations. In this case, a high level of general activity acted as a risk factor for suffering higher impairment.

The model containing developmental variables explained $23 \%$ of the variability, and the change produced is clinically important (31 points of difference in scoring, with a wide confidence interval). Experiencing a surgical intervention during the first month creates a vulnerability that predicts impairment in psychological functioning later in life - thus, problems may be based on organic difficulties or caused through interactions with others. Allen, Lewinsohn, and Seeley (1998) found that illness of the infant during the first year of life was predictive of anxiety disorders later in life, and they questioned if this association reflected a causal link or should be explained through the intervention of a common third factor. Whatever the influencing factors, biological hazards occurring very early in life may result in permanent sequels that have consequences in the psychosocial functioning of the child

Studies have found that, independent of their nature, life events increase the risk of later psychopathology or poor adaptation (Goodyer, 1993). However, it seems that the amount of risk present in the environment of the child is more important than the pattern of risk (Sameroff, Seifer, Baldwin, \& Baldwin, 1993). Our results indicate the pattern of physical abuse and other events, interpreted by the child as stressful, which cause a higher degree of impairment. More specifically, when the number of problems was considered, the only predictor of disturbed psychosocial functioning was the number of life events. Previous studies have related the increase in the number of stressful events and the increase of psychopathology (Adams, Overholser, \& Spirito, 1994; Biswas, Kapur, \& Kaliaperumal, 1995; Muratori \& Fasano, 1997; Vinnick \& Erickson, 1994), and it seems that the tendency is also true when the variable studied is impairment.

Contrary to results of recent studies, which indicate that an early age of onset of psychological problems is accompanied by indicators of greater severity (intensive and prolonged treatment, comorbidity) (Crowley,
Mikulich, MacDonald, Young, \& Zerbe, 1998; Giaconia et al., 1994; Hawkins et al., 1997; Lewisohn, Clarke, Seeley, \& Rohde, 1995), in our sample the higher the age of onset, the greater the impairment. However, clinically the results are of little significance (for every year of increase in the age of onset, the CGAS decreases almost 1.7 points in a decile), but they could indicate that adolescence may be a period of risk for the onset of psychopathology (Burke, Burke, Regier, \& Rae, 1990) and for the manifestation of more severe psychological problems. On the other hand, the severity indicators used by other authors differ to those we used. The data pertaining to duration of the symptoms are also of little clinical significance (for every 8 months of duration, the CGAS diminishes by 1 point), but in this case they are consistent with previous findings: the longer the duration of the problem, the greater the impairment (Thomsen, 1995).

Concerning the role of the family context as a marker of the severity of the problems of the child and how these problems alter his/her daily life, overprotection and rejection were the educational styles that led to worse functioning, whereas emotional warmth protected against impairment. McFarlane, Bellissimo, and Norman (1995) pointed out that low self-esteem and low social competence were the effects of overprotection and that good problem-solving skills and good impulse control were the effects of emotional warmth. These characteristics, in turn, could be related to the way the child copes with situations, and would alter or facilitate an optimal functioning.

Coping styles have been related to a higher or lower number of symptoms (avoidant vs. approach coping) (Herman-Stahl, Stemmler, \& Petersen, 1995), a good general behavioral adjustment (in the case of a style characterized by adjusting oneself to objective conditions) (Weisz, McCabe, \& Dennig, 1994), and decreasing behavioral disturbance (flexibility in coping) (Radovanovic, 1993). In our sample, those children who reported that in case of problems they would develop selfreliance (tried to see good things, to figure out how to deal with the problem) and investing in close friends (seek closeness and understanding from a peer), that is, those who used coping actions through the appraisal of the situation or focusing on the problem, were more impaired. The percentage of adjusted variability of the model $(18 \%$, one of the highest) indicates how important the way in which the child copes with the problem is, denoting how well he will be able to go on with a normal life. These results also point out to teaching coping strategies as a way of reducing the impact of the events.

Although we have analyzed independent models for the different groups of variables, it is clear that an interacting pathway exists. With regard to previously discussed issues, Smith (1995) pointed out that anxious or withdrawn temperamental traits and aggressive behaviors, along with stressful events, could result in the child becoming symptomatic, and hence, we could add, impaired; Wagner, Cohen, and Brook (1996) found that educational style was a moderator of the effect of life events: the association between stressful events and depressive symptoms was higher in families with harsh discipline vs. warm educational style. Additionally, McIntyre and Dusek (1995) observed that parental warmth and firm control were related to resolving the problems in a more adaptive way (focusing on the problem). Unfortunately, the amount of subjects partici- 
pating in this study did not permit an estimate of a unique model. However, in Table 2 we present a global model, based on the significant variables in the individual models, that will be a synthesis of the most relevant results. The mixed variables model, stressful events, and age and duration of psychopathology made the major contributions to the explanation of CGAS. As was expected, and previous authors have found, there exists a high degree of covariation among the variables, and many of them lost their importance when combined with other information. The resultant data would be informative of the most relevant variables, apart from psychopathology, for determining the degree of impairment the child could suffer. Clinicians would not rely simply on diagnostic information for establishing prognosis and severity of child and adolescent disorders.

In a developmental course, we could draw a sequence of high-risk markers of disturbed functioning, starting with high level of general activity as a temperamental trait, early developmental events such as surgery, and the addition/interaction of the rest of the significant variables, identifying adolescence as a period of high impact of dysfunction. The factors that protect against low functioning (that is, they are prognostic of better functioning) are: flexibility in adaptation to events, positive mood, low distractibility, the presence of a warm mother, marital harmony, as well as coping with problems by seeking the counsel of a professional (teacher or other).

The main limitation of the study was to create individual models because the number of variables was too big for the number of subjects. Bonferroni's correction was not applied, although a high number of analyses were conducted, because the goal was to create a unique model that explained child functioning in the light of different predictive variables. We also have to add the limitations related to retrospective assessment. Obviously, all the predictive variables occurred before the assessment of functional impairment, and functional impairment was scored only on the symptomatology of the DICA-R. Interviewers knew that our interest was to know how symptomatology affects functioning, and they were instructed to score the CGAS with symptomatology information only. So, if in the interview parents or child mentioned they had a new child in the house (stressful event), the knowledge of this fact did not affect CGAS score. Only if this newborn caused separation anxiety in the child, for example, and this separation anxiety provoked school absenteeism, would the CGAS score be influenced. The models were adjusted by psychopathology because we were interested in isolating the effect of having a disorder. Anyway, the high probability for introducing biases is well known, due to the problems for the interviewees of recalling past events accurately and of offering reliable and stable answers. We consider that, at present, enough empirical evidence and accumulated experience exists for reaffirming that recalled information can be obtained with useful accuracy using interview techniques to help the respondents minimize recall biases, as was the case for most of the information collected in the present study.

In spite of these limitations, this is the first study that has tried to ascertain which are the predictors of impairment using information from different contexts, with different methods and sources of information. We have shown that other variables distinct to psychopathology make their own specific contribution to impairment. Early identification of these conditions may assist in the development of early intervention and prevention efforts for the suffering children. Mental health professionals must be allowed to intervene and follow up with children who are at high risk of these conditions in order to provide them with adequate services and prevent the development of additional problems.

Acknowledgements - This work has been done courtesy of the grants DGICYT PM95-126 and DGICYT PM98-173 from the Ministry of Education and Culture (Spain).

\section{References}

Achenbach, T. M. (1991). Manual for the child behavior checklist/4-18 and 1991 profile. Burlington, VT: University of Vermont, Department of Psychiatry.

Adams, D. M., Overholser, J. C., \& Spirito, A. (1994). Stressful life events associated with adolescent suicide attempts. Canadian Journal of Psychiatry, 39, 43-48.

Allen, N. B., Lewinsohn, P. M., \& Seeley, J. R. (1998). Prenatal and perinatal influences on risk for psychopathology in childhood and adolescence. Development and Psychopathology, 10, 513-529.

Angold, A. A., Costello, E. J., Farmer, E., Burns, B. J., \& Erkanli, A. (1999). Impaired but undiagnosed. Journal of the American Academy of Child and Adolescent Psychiatry, 38, 129-137.

APA. (1987). Diagnostic and statistical manual of mental disorders-revised. Washington, DC: Author.

APA. (1994). Diagnostic and statistical manual of mental disorders- $I V$. Washington, DC: Author.

Apter, A., Orvaschel, H., Laseg, M., Moses, T., \& Tyano, S. (1989). Psychometric properties of the K-SADS-P in an Israeli adolescent inpatient population. Journal of the American Academy of Child and Adolescent Psychiatry, 28, $61-65$.

Bird, H., Canino, G., Rubio-Stipec, M., \& Ribera, J. C. (1987). Further measures of the psychometric properties of the Children's Global Assessment Scale. Archives of General Psychiatry, 44, 821-824.

Bird, H., Canino, G., Rubio-Stipec, M., Gould, M., Ribera, J., Sesman, M., Woodbury, M., Huertas-Goldman, S., Pagan, A., Sánchez-Lacay, A., \& Moscoso, M. (1988). Estimates of prevalence of childhood maladjustment in a community survey in Puerto Rico. Archives of General Psychiatry, 45, $1120-1126$.

Bird, H., Yager, T., Staghezza, B., Gould, M., Canino, G., \& Rubio-Stipec, M. (1990). Impairment in the epidemiological measurement of childhood psychopathology in the community. Journal of the American Academy of Child and Adolescent Psychiatry, 29, 796-803.

Bird, H. R., Shaffer, D., Fisher, P., Gould, M., Staghezza, B., Chen, J. Y., \& Hoven, C. (1993). The Columbia Impairment Scales (CIS): Pilot findings on a measure of global impairment for children and adolescents. International Journal of Methods in Psychiatric Research, 3, 167-176.

Biswas, A., Kapur, M., \& Kaliaperumal, V. G. (1995). Stressful life events and adjustment pattern of psychologically disturbed and nondisturbed children of the middle childhood period. Indian Journal of Clinical Psychology, 22, 7-13.

Brier, N. (1995). Predicting antisocial behavior in youngsters displaying poor academic achievement: A review of risk factors. Journal of Developmental and Behavioral Pediatrics, 16, 271-276.

Burke, K. C., Burke, J. D., Regier, D. A., \& Rae, D. S. (1990). Age at onset of selected mental disorders in five community populations. Archives of General Psychiatry, 47, 511-518.

Caspi, A., Henry, B., McGee, R. O., Moffitt, T. E., \& Silva, P. A. (1995). Temperament origins of child and adolescent behavior problems: From age three to fifteen. Child Development, 66, 55-68. 
Castro, J., Toro, J., Van der Ende, J., \& Arrindell, W. A. (1993). Exploring the feasibility of assessing perceived parental rearing styles in Spanish children with the EMBU. The International Journal of Social Psychiatry, 39, 47-57.

Clark, L. A. (1999). Introduction to the special section on the concept of disorder. Journal of Abnormal Psychology, 108, 371-373.

Conners, C. K. (1969). A teacher rating scale for use in drug studies with children. American Journal of Psychiatry, 126, 884-888.

Costello, E. J., Angold, A. A., \& Keeler, G. P. (1999). Adolescent outcomes of childhood disorders: The consequences of severity and impairment. Journal of the American Academy of Child and Adolescent Psychiatry, 38, 121-128.

Crowley, T. J., Mikulich, S. K., MacDonald, M., Young, S. E., \& Zerbe, G. O. (1998). Substance-dependent, conduct disordered adolescent males: Severity of diagnosis predicts 2years outcome. Drug and Alcohol Dependence, 49, 225-237.

Curtis, G. C., Magee, W. J., Eaton, W. W., Wittchen, H. U., \& Kessler, R. C. (1998). Specific fears and phobias: Epidemiology and classification. British Journal of Psychiatry, 173, 212-217.

Emery, R. E., \& O’Leary, K. D. (1982). Children's perception of marital discord and behavior problems of boys and girls. Journal of Abnormal Child Psychology, 10, 11-24.

Ezpeleta, L., Granero, R., \& de la Osa, N. (1999). Evaluación del deterioro en niños y adolescentes a través de la Children's Global Assessment Scale (CGAS). Revista de Psiquiatría Infanto-Juvenil, 1, 18-26.

Ezpeleta, L., de la Osa, N., Doménech, J. M., Navarro, J. B., \& Losilla, J. M. (1995). La Diagnostic Interview for Children and Adolescents-DICA-R: Acuerdo diagnóstico entre niños/adolescentes y sus padres. Revista de Psiquiatría de la Facultad de Medicina de Barcelona, 22, 153-163.

Ezpeleta, L., de la Osa, N., Doménech, J. M., Navarro, J. B., \& Losilla, J. M. (1997). Fiabilidad test-retest de la adaptación española de la Diagnostic Interview for Children and Adolescents-DICA-R. Psicothema, 9, 529-539.

Ezpeleta, L., de la Osa, N., Júdez, J., Doménech, J. M., Navarro, J. B., \& Losilla, J. M. (1997). Diagnostic agreement between clinician and the Diagnostic Interview for Children and Adolescents-DICA-R in a Spanish outpatient sample. Journal of Child Psychology and Psychiatry, 38, 431-440.

Giaconia, R. M., Reinherz, H. Z., Silverman, A. B., Pakiz, B., Frost, A. K., \& Cohen, E. (1994). Age of onset of psychiatric disorders in a community population of older adolescents. Journal of the American Academy of Child and Adolescent Psychiatry, 33, 706-717.

Goodyer, I. M. (1993). Recent stressful life events: Their long term effects. European Child and Adolescent Psychiatry, 2, $1-9$.

Granero, R., Ezpeleta, L., Doménech, J. M., \& de la Osa, N. (1998). Characteristics of the subjects and interview influencing the test-retest reliability of the Diagnostic Interview for Children and Adolescents-Revised. Journal of Child Psychology and Psychiatry, 39, 963-972.

Green, B., Shirk, S., Hanze, D., \& Wanstrath, J. (1994). The Children's Global Assessment Scale in clinical practice: An empirical evaluation. Journal of the American Academy of Child and Adolescent Psychiatry, 33, 1158-1164.

Grizenko, N., \& Pawliuk, N. (1994). Risk and protective factors for disruptive behavior disorders in children. American Journal of Orthopsychiatry, 64, 534-544.

Gureje, O., \& Omigbodun, O. O. (1995). Children with mental disorders in primary care: Functional status and risk factors. Acta Psychiatrica Scandinavica, 92, 310-314.

Harris, E. S., Canning, R. D., \& Kelleher, K. J. (1996). A comparison of measures of adjustment, symptoms, and impairment among children with chronic medical conditions. Journal of the American Academy of Child and Adolescent Psychiatry, 35, 1025-1032.
Hawkins, J. D., Graham, J. W., Maguin, E., Abbott, R., Hill, K. G., \& Catalano, R. F. (1997). Exploring the effects of age, alcohol use initiation and psychological risk factors on subsequent alcohol misuse. Journal of Studies on Alcohol, 58, 280-290.

Herman-Stahl, M. A., Stemmler, M., \& Petersen, A. C. (1995). Approach and avoidant coping: Implications for adolescent mental health. Journal of Youth and Adolescence, 24, 649-665.

Hodges, K. (1990, 1994, 1995) Child and Adolescent Functional Assessment Scale. Unpublished manuscripts, Vanderbilt Child Mental Health Services Evaluation project.

Hodges, K., Doucette-Gates, A., \& Liao, Q. (1999). The relationship between the Child and Adolescent Functional Assessment Scale (CAFAS) and indicators of functioning. Journal of Child and Family Studies, 8, 109-122.

Hodges, K., \& Wong, M. (1997). Use of the Child and Adolescent Functional Assessment Scale to predict service utilization and cost. Journal of Child and Family Studies, 5, 445-467.

Hodges, K., Wong, M., \& Latessa, M. (1998). Use of the Child and Adolescent Functional Assessment Scale (CAFAS) as an outcome measure in clinical settings. Journal of Behavioral Health Services Research, 25, 325-336.

Hollingshead, A. B. (1975). Four factor index of social status. Unpublished manuscript. Yale University, Department of Sociology.

Lavigne, J. V., Binns, H. J., Arend, R., Rosenbaum, D., Christoffel, K. K., Hayford, J. R., \& Gibbons, R. D. (1998). Psychopathology and health care use among preschool children: A retrospective analysis. Journal of the American Academy of Child and Adolescent Psychiatry, 37, 262-270.

Lewis, M. (1994). Chronic illness as a psychological risk factor in children. In W. B. Carey \& S. C. McDevitt (Eds.), Prevention and early intervention. Individual differences as risk factors for the mental health of children (pp. 103-112). New York: Brunner-Mazel.

Lewisohn, P. M., Clarke, G. N., Seeley, J. R., \& Rohde, P. (1995). Subgroups of adolescent depression: Reply. Journal of the American Academy of Child and Adolescent Psychiatry, 34, 831-833.

Lyons, J. S., O'Mahoney, M., Miller, S. I., Neme, J, Kabat, J., \& Miller, F. (1997). Predicting readmission to the psychiatric hospital in a managed care environment: Implications for quality indicators. American Journal of Psychiatry, 154, $337-340$.

Manassis, K., \& Hood, J. (1998). Individual and familial predictors of impairment in childhood anxiety disorders. Journal of the American Academy of Child and Adolescent Psychiatry, 37, 428-434.

McArdle, P., \& Gillett, T. (1997). Psychiatric inpatient treatment for children and adolescents in the UK: Criteria for admission. Israel Journal of Psychiatry and Related Sciences, 34, 195-199.

McFarlane, A. H., Bellissimo, A., \& Norman, G. R. (1995). Family structure, family functioning and adolescent wellbeing: The transcendent influence of parental style. Journal of Child Psychology and Psychiatry, 36, 847-864.

McIntyre, J. G., \& Dusek, J. B. (1995). Perceived parental rearing practices and styles of coping. Journal of Youth and Adolescence, 24, 499-509.

Muratori, F., \& Fasano, F. (1997). Life events, environmental variables and child depression. Psychopathology, 30, 111-117.

Nathan, P. E., \& Langenbucher, J. W. (1999). Psychopathology: Description and classification. Annual Review of Psychology, 50, 79-107.

Newman, D. L., Moffitt, T. E., Caspi, A., Magdol, L., Silva, P. A., \& Stanton, W. R. (1996). Psychiatric disorders in a birth cohort of young adults: Prevalence, comorbidity, clinical significance, and new case incidence from ages 11-21. Journal of Consulting and Clinical Psychology, 64, 552-562.

de la Osa, N., Ezpeleta, L., Doménech, E., Navarro, J. B., \& Losilla, J. M. (1996). Fiabilidad entre entrevistadores de la 
Entrevista Diagnóstica Estructurada para Niños y Adolescentes (DICA-R). Psicothema, 8, 359-368.

de la, Osa, N., Ezpeleta, L., Doménech, J. M., Navarro, J. B., \& Losilla, J. M. (1997). Convergent and discriminant validity of the Structured Diagnostic Interview for Children and Adolescents (DICA-R). Psychology in Spain, 1, 37-44.

Padur, J. S., Rapoff, M. A., Houston, B. K., Barnard, M., Danovsky, M., Olson, N., Moore, W. V., Vats, T. S., \& Lieberman, B. ( 1995). Psychosocial adjustment and the role of functional status for children with asthma. Journal of Asthma, 32, 345-353.

Patterson, J. M., \& McCubbin, H. I. (1987). Adolescent coping style and behaviors: Conceptualization and measures. Journal of Adolescence, 10, 163-186.

Perris, C., Jacobson, L., Lindström, H., Knorring, L., \& Perris, H. (1980). Development of a new inventory for assessing memories of parental rearing behavior. Acta Psychiatrica Scandinavica, 61, 265-274.

Radovanovic, H. (1993). Parental conflict and children's coping styles in litigating separated families: Relationships with children's adjustment. Journal of Abnormal Child Psychology, 21, 697-713.

Reich, W. (1992). Diagnostic Interview for Children and Adolescents. Pregnancy birth and preschool questionnaire (L. Ezpeleta, trans.). Unpublished manuscript, Washington University, School of Medicine, Department of Psychiatry, St. Louis.

Reich, W., Shayka, J., \& Taibleson, Ch. (1991). Diagnostic Interview for Children and Adolescents (L. Ezpeleta, trans.). Unpublished manuscript, Washington University, School of Medicine, Department of Psychiatry, St. Louis.

Roberts, R. E., Roberts, C. R., \& Chen, Y. R. (1997). Ethnocultural differences in prevalence of adolescent depression. American Journal of Community Psychology, 25, 95-110.

Sameroff, A. J., Seifer, R., Baldwin, A., \& Baldwin, C. (1993). Stability of intelligence from preschool to adolescence: The influence of social and family risk factors. Child Development, 64, 80-97.

Settertobulte, W., \& Kolip, P. (1997). Gender-specific factors in the utilization of medical services during adolescence. Journal of Adolescence, 20, 121-132.

Shaffer, D., Fisher, P., Dulcan, M. K., \& Davies, M. (1996). The NIMH Diagnostic Interview Schedule for Children Version 2.3 (DISC 2.3): Description, acceptability, prevalence rates, and performance in the MECA study. Journal of the American Academy of Child and Adolescent Pyschiatry, $35,865-877$.

Shaffer, D., Gould, M. S., Brasic, J., Ambrosini, P., Fisher, P., Bird, H., \& Aluwahlia, S. (1983). A Children's Global Assessment Scale (CGAS). Archives of General Psychiatry, $40,1228-1231$
Simonoff, E., Pickles, A., Meyer, J. M., Silberg, J. L., Maes, H. H., Loeber, R., Rutter, M., Hewitt, J. K., \& Eaves, L. J. (1997). The Virginia Twin Study of Adolescent Behavioral Development: Influence of age, sex, and impairment on rates of disorder. Archives of General Psychiatry, 54, 801-808.

Smith, J. C. (1995). More on stress-resilient children. Journal of the American Academy of Child and Adolescent Psychiatry, 34, 1403-1404.

Thomsen, P. H. (1995). Obsessive-compulsive disorder in children and adolescents: Predictors in childhood for long-term phenomenological course. Acta Psychiatrica Scandinavica, 92, 255-259.

Verhulst, F. C., Eussen, M. L. J., Berden, G., SandersWoudstra, J., \& Van der Ende, J. (1993). Pathways of problem behaviors from childhood to adolescence. Journal of the American Academy of Child and Adolescent Psychiatry, 32, 388-396.

Vinnick, L. A., \& Erickson, M. T. (1994). Social skill in third and sixth grade children: A moderator of lifetime stressful life events and behavior problems? Journal of Child and Family Studies, 3, 263-282.

Wagner, B. M., Cohen, P., \& Brook, J. (1996). Parent/ adolescent relationships: Moderators of the effects of stressful life events. Journal of Adolescent Research, 11, 347-374.

Wakefield, J. C. (1992). The concept of mental disorder: On the boundary between biological facts and societal values. American Psychologists, 47, 373-388.

Weissman, M. M., Warner, V., \& Fendrich, M. (1990). Applying impairment criteria to children's psychiatric diagnosis. Journal of the American Academy of Child and Adolescent Psychiatry, 29, 789-795.

Weisz, J. R., McCabe, M. A., \& Dennig, M. D. (1994). Primary and secondary control among children undergoing medical procedures: Adjustment as a function of coping style. Journal of Consulting and Clinical Psychology, 62, 324-332.

WHO. (1998). The international classification of impairments, disabilities, and handicaps [On line]. Available: http:// www.who.ch/whosis/icidh.htm.

WHO. (1999). ICIDH-2: International classification of functioning and disability. Beta-2 draft, Long version. Geneva: Author.

Windle, M., \& Lerner, R. M. (1986). Reassessing the dimensions of temperament individuality across the life span: The Revised Dimensions of Temperament Survey (DOTSR). Journal of Adolescent Research, 1, 213-230.

Manuscript accepted 24 January 2000 